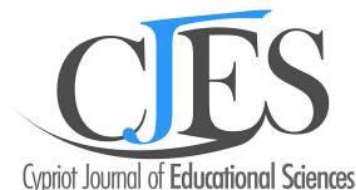

www.cjes.eu

\title{
Sudoku puzzles for practicing SI prefixes: A case study with Turkish undergraduates
}

Handan Urek $^{\mathrm{a} *}$, Balıkesir University, Necatibey Education Faculty, Mathematics and Science Education Dept., Altıeylül / Balıkesir / Turkey, https://orcid.org/0000-0002-3593-8547

\section{Suggested Citation:}

Urek, H. (2020). Sudoku puzzles for practicing SI prefixes: A case study with Turkish undergraduates. Cypriot Journal of Educational Science, 15(5), 1065-1077. https://doi.org/10.18844/cjes.v15i5.5152

Received from May 15, 2020; revised from August 20, 2020; accepted from October15, 2020.

(C2020 Birlesik Dunya Yenilik Arastirma ve Yayincilik Merkezi. All rights reserved.

\section{Abstract}

The purpose of this study was to develop two Sudoku puzzles for undergraduate students which can be utilised in the context of introductory physical science courses in order to assist them to practice SI prefixes. For this reason, SI prefixes for decimal multiples and submultiples were addressed in two separate puzzles. To test the puzzles, a case study was conducted with 20 biology teaching students studying their first year in a state university in Turkey. Data were collected with the help of a questionnaire posed to the students before and after the application of the puzzles. According to the results, 18 students (90\%) completed the puzzles successfully. In addition, the students agreed that solving the Sudoku puzzles made contributions to them in terms of practicing SI prefixes. It is recommended that the Sudoku puzzles developed in this study might be used efficiently for all undergraduate students taking courses such as general chemistry and physics.

Keywords: SI prefixes, educational games, Sudoku puzzles, introductory science courses.

*ADDRESS FOR CORRESPONDENCE: Handan Urek, Balıkesir University, Necatibey Education Faculty, Mathematics and Science 


\section{Introduction}

Mostly, introductory physical science courses at the university level begin with a chapter focusing on many subjects, such as measurement in science, units, systems, standards and significant numbers. The same beginning is also encountered in the textbooks related to those courses (Ebbing \& Gammon, 2002; Petrucci, Herring, Madura \& Bisonnette, 2012; Serway \& Beichner, 2002; Stanford \& Tanner, 2014). Those subjects act as a prerequisite because they help the students to comprehend the content of subsequent subjects in the courses. One of those subjects is related to decimal multiples and submultiples.

The measurement takes an important place in physical sciences and the value of a quantity measured is defined with a unit (Coramik \& Ozdemir, 2020). There are several measurement systems that deal with different units. A practical and suitable measurement system is the System International (SI) which was called the metre-kilogram-second (MKS) system earlier (Steele \& Wood, 2020). The centimetre-gram-second (CGS) system of units is a variant of the metric system of physical units (Abdukadyrov, 2018). There is also the British engineering system which takes yard, pound and second as its standards (Stanford \& Tanner, 2014). The measurement results in a numerical value which might be on a smaller or a larger scale. In such cases, those values are required to be organised with decimal multiples and submultiples. Decimal multiples and submultiples are denoted according to SI as shown in Table 1 (Thompson \& Tyler, 2008).

Table 1. SI prefixes

\begin{tabular}{cccccc}
\hline Prefix & Symbol & Factor & Prefix & Symbol & Factor \\
\hline yotta & $\mathrm{Y}$ & $10^{24}$ & deci & $\mathrm{d}$ & $10^{-1}$ \\
zetta & $\mathrm{Z}$ & $10^{21}$ & centi & $\mathrm{c}$ & $10^{-2}$ \\
exa & $\mathrm{E}$ & $10^{18}$ & milli & $\mathrm{m}$ & $10^{-3}$ \\
peta & $\mathrm{P}$ & $10^{15}$ & micro & $\mu$ & $10^{-6}$ \\
tera & $\mathrm{T}$ & $10^{12}$ & nano & $\mathrm{n}$ & $10^{-9}$ \\
giga & $\mathrm{G}$ & $10^{9}$ & pico & $\mathrm{p}$ & $10^{-12}$ \\
mega & $\mathrm{M}$ & $10^{6}$ & femto & $\mathrm{f}$ & $10^{-15}$ \\
kilo & $\mathrm{k}$ & $10^{3}$ & atto & $\mathrm{a}$ & $10^{-18}$ \\
hecto & $\mathrm{h}$ & $10^{2}$ & zepto & $\mathrm{z}$ & $10^{-21}$ \\
deka & $\mathrm{da}$ & $10^{1}$ & yocto & $\mathrm{y}$ & $10^{-24}$ \\
\hline
\end{tabular}

According to Table 1, organising the numerical values with decimal multiples and submultiples gives rise to representing the quantities with the help of prefixes which come before the unit. Those quantities might be larger numerical values indicated by decimal multiples: $10^{1}, 10^{2}, 10^{3} \ldots$, whereas smaller values are indicated by decimal submultiples: $10^{-1}, 10^{-2}, 10^{-3} \ldots$. Each of those values has specific names as prefixes and symbols to mark the quantity shown by a unit. Those symbols are mostly shown with Latin letters, such as $\mathrm{K}\left(\right.$ for $\left.10^{3}\right)$, $\mathrm{n}\left(\right.$ for $10^{-9}$ ) and $\mathrm{T}\left(\right.$ for $10^{12}$ ). Also, the Greek letter, $\mu$, is utilised for denoting a small number, $10^{-6}$. At this point, science comes to the fore when symbols and units are concerned, as stated by Oguzhan Dincer and Osmanoglu (2018). For example, 1,000 grams is 1 kilogram. The prefix, kilo is learnt in the early primary school years. However, this knowledge supplies a base for learning other numerical expressions such as kPa (kilopascal), kcal (kilocalorie), kJ (kilojoule), kV (kilovolt), km (kilometre), kW (kilowatt) and kA (kiloampere) which are used in different grade levels. As can be seen, the same prefix is used to indicate various quantities related to different units in the fields of biology, chemistry and physics.

In addition to the use of the above-mentioned quantities in physical science courses, individuals who are interested in information technologies, as well as students studying at this field, should possess sufficient literacy related to decimal multiples. For example, one should know the meaning of a gigabyte (GB) while buying a flash disk or laptop. GBs are often used to measure the storage capacity of digital versatile disks (DVDs), random access memories (RAMs) and hard drives (Christensson, 
2013). The storage capacity may also be indicated in kilobyte (KB), megabyte (MB) and terabyte (TB), depending on the data to be stored in accordance with the SI prefixes (Tech Terms, 2012). Moreover, every individual makes use of several SI prefixes in daily life. Therefore, it can be stated that SI prefixes have a wide range of use from the field of science to technology and from education to daily life. This article focuses on the issue from the aspects of science education and university students.

Besides their wide range of use, all of the units and symbols might be challenging for the students to learn and apply during science courses. The literature indicates that students experience difficulties with units (Bagno, Berger \& Eylon, 2008; Furio, Azcona \& Guisasola, 2002; Ogunleye, 2009; Oguzhan Dincer \& Osmanoglu, 2018; Tan Sisman \& Aksu, 2016; Urek \& Dolu, 2018). In their study, Tan Sisman and Aksu (2016) found that sixth-grade students held a wide range of misconceptions and errors related to units used for linear, area and volume measurements. Bagno et al. (2008) determined that $67 \%$ of the high school physics students had difficulties showing that the units on the right side of a formula were identical to the units on the left side of it for the kinematics and dynamics formulae. Also, Ogunleye (2009) found that senior secondary school students and their teachers indicated the confusion arising from units and their conversions as a reason for their inability to solve physics problems. Additionally, in their studies, Oguzhan Dincer and Osmanoglu (2018) and Urek and Dolu (2018) determined that science teacher candidates did not have a satisfying performance related to unit conversion. Moreover, Furio et al. (2002) reported that university-level chemistry students did not identify 'mole' as a unit; they did not know its meaning and they avoided using it. All of those findings show that middle school, high school and university students possess problems in using units effectively. Students' performance on tasks dealing with size and scale is correlated to their knowledge of units (Delgado, 2013). In addition, units are generally used with SI prefixes to remark the quantities. Hence, it is thought that the students' ability to utilise SI prefixes correctly should be improved.

Researchers are trying to develop effective methods and techniques to eliminate students' difficulties in learning various subjects in science education. One of such techniques is educational games. de Freitas (2018) points out that educational games are overwhelmingly effective learning tools. Those games might be based on computer applications as well as face-to-face practices. The research results indicate that educational games in science education increase students' achievement (Coskun, Akarsu \& Kariper, 2012; Yazicioglu \& Cavus-Gungoren, 2012), motivation towards learning (Bulus Kirikkaya, Iseri \& Vurkaya, 2010; Yazicioglu \& Cavus-Gungoren, 2012) and attitudes towards science course (Yazicioglu \& Cavus-Gungoren, 2012). Besides, educational games are reported to supply the retention of the subjects which are determined to be difficult by the students (Karamustafaoglu, Pazar \& Karamustafaoglu, 2018). Sudoku puzzles are one of the games adapted for educational purposes.

\subsection{What is a Sudoku puzzle?}

Sudoku puzzles are asserted as one type of educational games in addition to being a popular puzzle worldwide, which originated in Japan. In Japanese, Sudoku is the abbreviation for a single number which refers to completing the grids in a number-placement puzzle with the digits without any repetition (Wu, Zhou, Agaian \& Noonan, 2016). A basic Sudoku puzzle includes partially filled cells (Ernstberger \& Venkataramanan, 2018). Sudoku puzzles might have a different number of cells. For example, $4 \times 4$ cells involve four $2 \times 2$ cell blocks; $6 \times 6$ cells involve six $3 \times 2$ cell blocks. Increasing the number of cells in the game results in the formation of a more challenging Sudoku puzzle, whereas it becomes easier to complete when Sudoku is constructed with a smaller number of cells. Traditionally, a Sudoku puzzle consists of $9 \times 9$ cells; nine rows and nine columns (Snyder, 2010). Those $9 \times 9$ cells involve nine $3 \times 3$ cell blocks.

The name of the Sudoku puzzle itself describes the only rule of the game: The game is based on inserting elements in rows and columns without any recurrence (Bittar et al., 2009). The elements 
inserted are mostly numbers. Thus, as Chytry (2014) explains, the numbers in rows, columns and in $3 \times$ 3 blocks are not repeated and the order of numbers when filling is not important.

\subsection{Literature review}

Although Sudoku puzzles are originally based on numbers from one to nine, it is seen that they are adapted for educational purposes by replacing the numbers with the elements from school subjects. Sudoku puzzles are inexpensive and creative which can be used to promote students' problem-solving skills by teachers (Tengah, 2011). They can be based on paper-pencil or computer (Ernstberger \& Venkataramanan, 2018). Completing a Sudoku puzzle requires pattern recognition and logic (Perez \& Lamoureux, 2007). Also, they motivate the students. In the literature, there are Sudoku puzzles designed for different age levels, such as kindergarten (Guven, Gultekin \& Dedeoglu, 2020), primary school (Tengah, 2011), middle school (Rukavina, Zuvic-Butorac, Ledic, Milotic \& Jurdana-Sepic, 2012; Tengah, 2011), high school (Jolliff, 2007) and university-level students (Perez \& Lamoureux, 2007).

Sudoku puzzles are widespread in the area of mathematics education. Mathematics educators have utilised Sudoku puzzles for the introduction of proof techniques (Snyder, 2010), the concepts of matrix, permutation and modular functions (Evans, Lindner \& Shi, 2011) and graph theory (Chytry, 2014). Also, Sudoku puzzles are encountered in science education. The concepts of elements (Bittar et al., 2009), functional groups (Crute \& Myers, 2007), transitional elements (Welsh, 2007), genetic algorithm (Ernstberger \& Venkataramanan, 2018) and amino acids (Perez \& Lamoureux, 2007) were addressed in the Sudoku puzzles developed. Besides, in his study, Jolliff (2007) described Sudoku puzzles to teach ions to gifted students. As can be seen, several chemistry subjects are popular with Sudoku applications in science education.

The above-mentioned literature suggests that Sudoku puzzles can be utilised for supporting the learning of students in various grade levels with different educational needs in the form of an educational game. Additionally, there is a need for effective student-centred learning activities which can be applied easily and safely in the field of science education.

\subsection{The aim and significance of the study}

In this study, it is intended to develop two Sudoku puzzles for undergraduate students taking introductory physical science courses to make them practice the SI prefixes.

The study is believed to be significant in enhancing university students' comprehensions about $\mathrm{SI}$ prefixes and their symbols. It is expected to overcome students' learning difficulties in this respect. In addition, it is intended to present an activity for undergraduate students in the form of an educational game. Thus, it is expected to make a contribution to the content of activities which can be utilised in the context of science education.

\section{Method}

\subsection{Study design}

The study aims to develop and present two Sudoku puzzles for university students to practice the SI prefixes. Hence, the study involves both theoretical and practical parts. The theoretical part of the study involves the construction of Sudoku puzzles based on the literature. The practical part involves the application of the puzzles to the participants for testing them in addition to posing several openended questions to the participants in the pre- and post-application period. Thus, a case study was conducted. The case study aims to create detailed descriptions related to a case and define the case in its present state (Buyukozturk, Kilic Cakmak, Akgun, Karadeniz \& Demirel, 2010). In this way, the study was designed. 


\subsection{The participants}

The participants included 20 first-year biology teaching students studying in the education faculty of a state university located in the western part of Turkey. Eighteen of the students were female, whereas two of them were male. The study was conducted in the beginning of the 2019-2020 academic year spring term. In this term, the students were taking introductory chemistry and biology courses with their laboratory applications.

The participants were determined by means of critical case sampling from purposeful sampling methods. This method allows the researcher to make such an interpretation, 'if this case happens in this sampling, it certainly happens in similar settings' (Yildirim \& Simsek, 2008). This method is asserted to be efficient if the researcher has limited sources to investigate the case. In the present case, biology teaching first-year students were included in the study sample because they were taking introductory chemistry and chemistry laboratory courses given in the spring term of the first year of their programme and using the SI prefixes in their studies. Also, the participants were the students the researcher taught. Besides, the participants were taking general biology and biology laboratory applications in the spring term of their first year. However, their programme did not include the introductory physics course and its laboratory applications. Thus, it might be concluded that Sudoku puzzles will also work for the undergraduate students who take more introductory physical science courses (such as introductory physics), if they work well for biology teaching students.

\subsection{Data collection instrument}

Data were collected with the help of a questionnaire consisting of open-ended questions and two Sudoku puzzles developed by the researcher. In educational researches, measurement instruments are used for several purposes, such as evaluation of the effectiveness of instruction and determination of learning deficiencies (Buyukozturk et al., 2010). In this regard, content validity is reported to be related to how the items in the test represent the behaviours which are wanted to be measured. In the present study, the questionnaire was applied to the students to investigate the effectiveness of the Sudoku puzzles. To obtain the content validity of the questionnaire, it was first presented to three experts from the science education field and then the questionnaire was revised according to their opinions.

The questionnaire began with the presentation of the table of SI prefixes for the factors from $10^{-21}$ to $10^{21}$ considering decimal multiples and submultiples. The participants were asked to examine the table. Then, several questions were posed to the students in the pre-application period of the puzzles. Those questions considered participants' most frequently used SI prefixes and most frequent utilisation fields for those prefixes in addition to the prefixes which have never been heard of by the participants. Next, the questionnaire presented two Sudoku puzzles and the students were asked to complete them. At this point, necessary instructions were given to the participants in relation to the Sudoku puzzles. Finally, several open-ended questions were posed to the students in relation to their experience for solving the puzzles in the post-application period. Those questions addressed students' opinions related to the applicability, difficulty and benefits of the Sudoku puzzles.

\subsubsection{Development of the Sudoku puzzles}

In the study, the SI prefixes for decimal multiples and submultiples were handled in two separate Sudoku puzzles. Both puzzles were based on nine blocks of $3 \times 3$ elements. Thus, nine elements needed to be inserted in each puzzle. The Sudoku puzzle developed for practicing the SI prefixes for decimal multiples involved the following elements: $D, H, K, M, G, T, P, E$ and $Z$. This puzzle is called Sudoku 1 in the following sections of this article. The second puzzle developed for practicing the $S I$ prefixes for decimal submultiples involved the following elements: $d, c, m, \mu, n, p, f$, a and $z$. This puzzle is called Sudoku 2 in the following sections of this article. 
While developing the Sudoku puzzles, it is crucial to construct them with a working pattern. The Sudoku puzzles developed in this study were based on the pattern utilised in the study of Perez and Lamoureux (2007). Another important point is the level of difficulty in the Sudoku puzzles. The difficulty level might be mild, difficult and fiendish as reported by Lee, Goodwin and Johnson-Laird (2008). In this study, it is intended to avoid developing a fiendish Sudoku puzzle since there might be several students who are not familiar with this game. The puzzles developed in the study are shown in Figures 1 and 2. The answers to the puzzles are shown in red in Figures 3 and 4, respectively.

\begin{tabular}{|c|c|c|c|c|c|c|c|c|}
\hline & M & & $\mathbf{P}$ & & & $\mathbf{h}$ & $\mathbf{G}$ & \\
\hline $\mathbf{k}$ & $\mathbf{h}$ & & & $\mathbf{E}$ & $\mathbf{M}$ & & $\mathbf{d a}$ & \\
\hline $\mathbf{d a}$ & & $\mathbf{T}$ & & $\mathbf{k}$ & $\mathbf{Z}$ & $\mathbf{M}$ & & $\mathbf{E}$ \\
\hline $\mathbf{E}$ & $\mathbf{Z}$ & $\mathbf{k}$ & & $\mathbf{h}$ & $\mathbf{P}$ & $\mathbf{d a}$ & & \\
\hline & & $\mathbf{G}$ & & $\mathbf{d a}$ & & $\mathbf{T}$ & & \\
\hline & & $\mathbf{d a}$ & $\mathbf{M}$ & $\mathbf{Z}$ & & $\mathbf{E}$ & $\mathbf{k}$ & $\mathbf{P}$ \\
\hline $\mathbf{P}$ & & $\mathbf{h}$ & $\mathbf{Z}$ & $\mathbf{M}$ & & $\mathbf{G}$ & & $\mathbf{d a}$ \\
\hline & $\mathbf{k}$ & & $\mathbf{d a}$ & $\mathbf{G}$ & & & $\mathbf{E}$ & $\mathbf{M}$ \\
\hline & $\mathbf{d a}$ & $\mathbf{M}$ & & & $\mathbf{T}$ & & $\mathbf{Z}$ & \\
\hline
\end{tabular}

Figure 1. The Sudoku puzzle developed for practicing the SI prefixes for decimal multiples (Sudoku 1)

\begin{tabular}{|c|c|c|c|c|c|c|c|c|}
\hline & $\boldsymbol{\mu}$ & & $\mathbf{f}$ & & & $\mathbf{c}$ & $\mathbf{n}$ & \\
\hline $\mathbf{m}$ & $\mathbf{c}$ & & & $\mathbf{a}$ & $\boldsymbol{\mu}$ & & $\mathbf{d}$ & \\
\hline $\mathbf{d}$ & & $\mathbf{p}$ & & $\mathbf{m}$ & $\mathbf{z}$ & $\boldsymbol{\mu}$ & & $\mathbf{a}$ \\
\hline $\mathbf{a}$ & $\mathbf{z}$ & $\mathbf{m}$ & & $\mathbf{c}$ & $\mathbf{f}$ & $\mathbf{d}$ & & \\
\hline & & $\mathbf{n}$ & & $\mathbf{d}$ & & $\mathbf{p}$ & & \\
\hline & & $\mathbf{d}$ & $\boldsymbol{\mu}$ & $\mathbf{z}$ & & $\mathbf{a}$ & $\mathbf{m}$ & $\mathbf{f}$ \\
\hline $\mathbf{f}$ & & $\mathbf{c}$ & $\mathbf{z}$ & $\boldsymbol{\mu}$ & & $\mathbf{n}$ & & $\mathbf{d}$ \\
\hline & $\mathbf{m}$ & & $\mathbf{d}$ & $\mathbf{n}$ & & & $\mathbf{a}$ & $\boldsymbol{\mu}$ \\
\hline & $\mathbf{d}$ & $\boldsymbol{\mu}$ & & & $\mathbf{p}$ & & $\mathbf{z}$ & \\
\hline
\end{tabular}

Figure 2. The Sudoku puzzle developed for practicing the SI prefixes for decimal submultiples (Sudoku 2)

\begin{tabular}{|c|c|c|c|c|c|c|c|c|}
\hline & M & E & P & T & da & $\mathbf{h}$ & $\mathbf{G}$ & $\mathbf{k}$ \\
\hline $\mathbf{k}$ & $\mathbf{h}$ & $\mathbf{P}$ & $\mathbf{G}$ & $\mathbf{E}$ & $\mathbf{M}$ & $\mathbf{Z}$ & $\mathbf{d a}$ & $\mathbf{T}$ \\
\hline da & $\mathbf{G}$ & $\mathbf{T}$ & $\mathbf{h}$ & $\mathbf{k}$ & $\mathbf{Z}$ & $\mathbf{M}$ & $\mathbf{P}$ & $\mathbf{E}$ \\
\hline $\mathbf{E}$ & $\mathbf{Z}$ & $\mathbf{k}$ & $\mathbf{T}$ & $\mathbf{h}$ & $\mathbf{P}$ & $\mathbf{d a}$ & $\mathbf{M}$ & $\mathbf{G}$ \\
\hline $\mathbf{M}$ & $\mathbf{P}$ & $\mathbf{G}$ & $\mathbf{k}$ & $\mathbf{d a}$ & $\mathbf{E}$ & $\mathbf{T}$ & $\mathbf{h}$ & $\mathbf{Z}$ \\
\hline $\mathbf{h}$ & $\mathbf{T}$ & $\mathbf{d a}$ & $\mathbf{M}$ & $\mathbf{Z}$ & $\mathbf{G}$ & $\mathbf{E}$ & $\mathbf{k}$ & $\mathbf{P}$ \\
\hline $\mathbf{P}$ & $\mathbf{E}$ & $\mathbf{h}$ & $\mathbf{Z}$ & $\mathbf{M}$ & $\mathbf{k}$ & $\mathbf{G}$ & $\mathbf{T}$ & $\mathbf{d a}$ \\
\hline $\mathbf{T}$ & $\mathbf{k}$ & $\mathbf{Z}$ & $\mathbf{d a}$ & $\mathbf{G}$ & $\mathbf{h}$ & $\mathbf{P}$ & $\mathbf{E}$ & $\mathbf{M}$ \\
\hline $\mathbf{G}$ & $\mathbf{d a}$ & $\mathbf{M}$ & $\mathbf{E}$ & $\mathbf{P}$ & $\mathbf{T}$ & $\mathbf{k}$ & $\mathbf{Z}$ & $\mathbf{h}$ \\
\hline
\end{tabular}

Figure 3. Answers of the Sudoku 1 


\begin{tabular}{|c|c|c|c|c|c|c|c|c|}
\hline & $\boldsymbol{\mu}$ & $\mathbf{a}$ & $\mathbf{f}$ & $\mathbf{p}$ & $\mathbf{d}$ & $\mathbf{c}$ & $\mathbf{n}$ & $\mathbf{m}$ \\
\hline $\mathbf{m}$ & $\mathbf{c}$ & $\mathbf{f}$ & $\mathbf{n}$ & $\mathbf{a}$ & $\boldsymbol{\mu}$ & $\mathrm{z}$ & $\mathbf{d}$ & $\mathbf{p}$ \\
\hline $\mathbf{d}$ & $\mathbf{n}$ & $\mathbf{p}$ & $\mathbf{c}$ & $\mathbf{m}$ & $\mathbf{z}$ & $\boldsymbol{\mu}$ & $\mathbf{f}$ & $\mathbf{a}$ \\
\hline $\mathbf{a}$ & $\mathbf{z}$ & $\mathbf{m}$ & $\mathbf{p}$ & $\mathbf{c}$ & $\mathbf{f}$ & $\mathbf{d}$ & $\boldsymbol{\mu}$ & $\mathbf{n}$ \\
\hline $\boldsymbol{\mu}$ & $\mathbf{f}$ & $\mathbf{n}$ & $\mathbf{m}$ & $\mathbf{d}$ & $\mathbf{a}$ & $\mathbf{p}$ & $\mathbf{c}$ & $\mathbf{z}$ \\
\hline $\mathbf{c}$ & $\mathbf{p}$ & $\mathbf{d}$ & $\boldsymbol{\mu}$ & $\mathbf{z}$ & $\mathbf{n}$ & $\mathbf{a}$ & $\mathbf{m}$ & $\mathbf{f}$ \\
\hline $\mathbf{f}$ & $\mathbf{a}$ & $\mathbf{c}$ & $\mathbf{z}$ & $\boldsymbol{\mu}$ & $\mathbf{m}$ & $\mathbf{n}$ & $\mathbf{p}$ & $\mathbf{d}$ \\
\hline $\mathbf{p}$ & $\mathbf{m}$ & $\mathbf{z}$ & $\mathbf{d}$ & $\mathbf{n}$ & $\mathbf{c}$ & $\mathbf{f}$ & $\mathbf{a}$ & $\boldsymbol{\mu}$ \\
\hline $\mathbf{n}$ & $\mathbf{d}$ & $\boldsymbol{\mu}$ & $\mathbf{a}$ & $\mathbf{f}$ & $\mathbf{p}$ & $\mathbf{m}$ & $\mathbf{z}$ & $\mathbf{c}$ \\
\hline
\end{tabular}

Figure 4. Answers of the Sudoku 2

The developmental stage of the Sudoku puzzles involved two pilot studies to test them. For this reason, preliminary research was conducted with five university students taking introductory science courses. Data obtained from the pilot studies helped the researcher to check the pattern structure and difficulty level of the puzzles, in addition to determining the possible time interval for the students to solve them.

\subsection{Data collection process and data analysis}

The data collection process was fulfilled with the application of the questionnaire to all participants in the context of their chemistry laboratory applications in two course hours. Students were provided with necessary instructions at the beginning of the study. Also, it was underlined that attendance in the study was based on voluntariness. Thus, data were obtained and the collected data were analysed by means of qualitative approaches. Content analysis was conducted for the responses given to the open-ended questions. The content analysis aims to determine certain words or conceptions in a text (Buyukozturk et al., 2010). In this way, the researcher tried to reach interpretations related to the meanings of those words and conceptions. In this process, the reliability of data analysis is provided by examining the consistency with a researcher outside the study (Yildirim \& Simsek, 2008). In the study, an expert from the science education field was asked to check the approach in forming the categories in data analysis. Besides, the Sudoku puzzles completed by the students were checked by comparing them to the answer key to find out if they were correct or incorrect. Therefore, the findings were obtained for the study.

\section{Results}

\subsection{Results obtained from the pre-application period of the Sudoku puzzles}

In the pre-application period, the participants were first asked for their most-used SI prefixes. It was found that all of the participants $(n=20)$ asserted 'kilo' as their most used SI prefix. This response was followed by 'milli' $(n=14)$ and 'centi' $(n=11)$. Also, 'mega' $(n=6)$, 'micro' $(n=6)$ and 'giga' $(n=4)$ were among their responses. Besides, several prefixes were found in lower frequencies, such as 'nano' $(n=3)$, 'hecto' $(n=2)$, 'deci' $(n=2)$ and 'deca' $(n=1)$.

Second, the participants were asked to indicate the fields that they used SI prefixes most. The most frequent response of the participants indicated the numerical courses $(n=13)$. The participants mentioned physics, chemistry, biology and mathematics courses in this respect. Next, they stated that they utilised SI prefixes for indicating mass during shopping and cooking $(n=12)$. Also, they mentioned the use of SI prefixes for indicating distance $(n=3)$ and length $(n=2)$. Moreover, several responses were found to be given by single participants. Those participants signified the utilisation of SI prefixes while 
buying technological devices $(n=1)$, uploading to the internet on the mobile phone $(n=1)$, saving files to the computer $(n=1)$ and calculating the electrical energy consumed $(n=1)$.

Third, the participants were asked if there were any SI prefixes which they had not heard before. All of the participants $(n=20)$ pointed out that there were unknown SI prefixes when they considered the table given to them at the beginning of the application. Table 2 demonstrates the frequency distribution of participants' unknown SI prefixes.

Table 2. Participants' unknown SI prefixes

\begin{tabular}{cccc}
\hline $\begin{array}{c}\text { Unknown } \\
\text { SI Prefix }\end{array}$ & $f$ & $\begin{array}{c}\text { Unknown } \\
\text { SI Prefix }\end{array}$ & $f$ \\
\hline $\mathrm{z}$ & 20 & $\mathrm{G}$ & 9 \\
$\mathrm{a}$ & 18 & $\mathrm{~d}$ & 5 \\
$\mathrm{f}$ & 16 & $\mathrm{c}$ & 5 \\
$\mathrm{E}$ & 15 & $\mu$ & 4 \\
$\mathrm{Z}$ & 14 & $\mathrm{~h}$ & 3 \\
$\mathrm{~T}$ & 12 & $\mathrm{n}$ & 2 \\
$\mathrm{P}$ & 11 & $\mathrm{M}$ & 1 \\
$\mathrm{p}$ & 10 & $\mathrm{~m}$ & 1 \\
\hline
\end{tabular}

3.2 Results obtained from the post-application period of the Sudoku puzzles

After the application of the Sudoku puzzles, it was found that 18 of the students $(90 \%)$ completed both of them correctly. On the other hand, two students (10\%) signified that they were unable to complete the Sudoku puzzles. Figure 5 shows the results related to the application of the Sudoku puzzles. The findings in the following section are related to the experiences and opinions of the participants who completed the Sudoku puzzles successfully $(n=18)$.

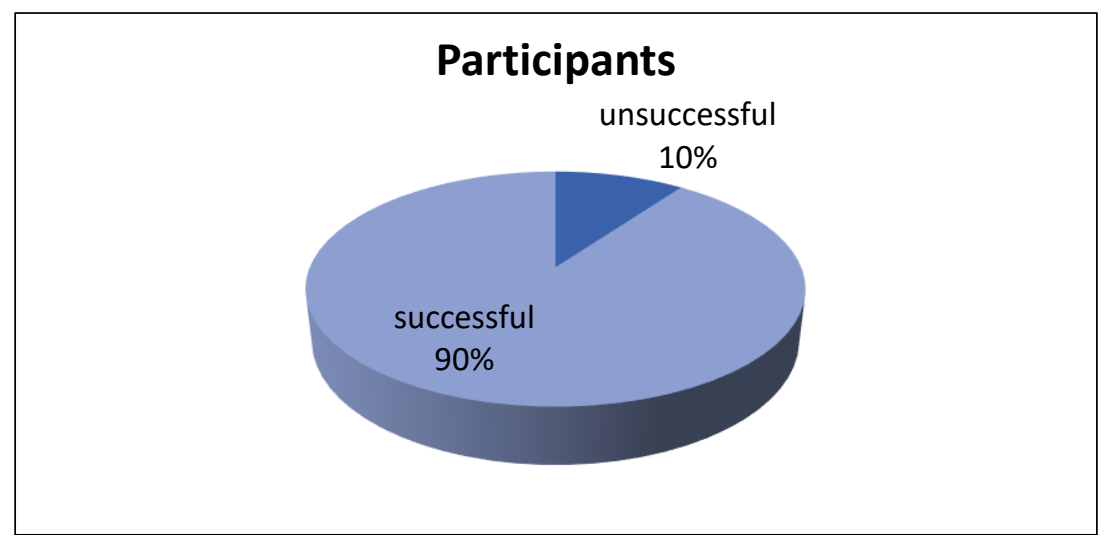

Figure 5. The results obtained from the participants related to the application of the Sudoku puzzles 
In the post-application period, the participants were first asked to determine the time to complete each Sudoku. According to the calculations, the average time to complete Sudoku 1 for 18 students was found to be about 23 minutes and the average time to complete Sudoku 2 was found to be about 30 minutes. Afterwards, the participants were asked to determine which Sudoku puzzle was more difficult for them to complete. According to their responses, 10 participants stated that Sudoku 2 was more difficult than Sudoku 1, whereas eight participants stated that Sudoku 1 was more difficult than Sudoku 2.

The participants were also asked whether the Sudoku puzzles made contributions to them in terms of practicing SI prefixes. All of the students $(n=18)$ replied that the puzzles made contributions to them in this respect. Statements of students' responses are given below. it.

Student 2: The puzzles made me think about the SI prefix and which derivative of 10 while filling in

Student 6: Definitely, this intelligence game helped me to comprehend those scientific concepts, SI prefixes. Also, it activated my visual intelligence and the symbols became clear in my mind.

Student 12: It was easier to learn and they still stay in my memory because I made them by practicing, not based on memorisation.

Student 13: Yes, it made contributions to me in terms of practicing the SI prefixes. I learnt SI prefixes related to large and small numbers that I do not know.

Finally, the students were asked if they enjoyed themselves during their experience with the Sudoku puzzles. Similar to the previous question's findings, all of them indicated positive responses to this question. Several statements of students' responses are presented below.

Student 1: If you asked me to memorise the SI prefixes, I would probably forget them all in a week. However, this activity assisted me to learn them both in an enjoyable way and use my brain more. I would like to see similar activities in terms of other courses also.

Student 7: In the beginning, I experienced difficulty. However, it became enjoyable when I got familiar with it.

Student 8: Yes, I felt happy when I saw the activity sheet. I did not understand how time passed while I was solving them. I would make all of them even you asked me to solve ten more such puzzles.

Student 17: Yes, I did it fondly. Thus, it helped me to enhance my knowledge related to decimal multiples and submultiples.

\section{Discussion}

The results obtained in the pre-application period of the Sudoku puzzles signified several deficiencies of the participants in relation to SI prefixes. The SI prefixes, such as mega, nano, centi, milli, hecto, micro, deci and giga, were also among their unknown prefixes. This result supports the finding obtained from Oguzhan Dincer and Osmanoglu's (2018) study, implying that science teacher candidates experience difficulties in the conversion of units from gigametre to nanometre and $\mathrm{mg}$ to g. Besides, the participants mostly mentioned numerical courses for the most frequent utilisation fields of SI prefixes. Accordingly, various research studies are seen to deal with the use of units in terms of school subjects in physics (Bagno et al., 2008), chemistry (Furio et al., 2002; Urek \& Dolu, 2018) or by integrating science and mathematics (Oguzhan Dincer \& Osmanoglu, 2018) in this respect. On the other hand, there were single responses for the use of SI prefixes in the field of technology. This result is in line with one of the findings of the study by Incantalupo, Treagust and Koul (2014) conducted with high-school students to measure their knowledge and attitudes towards technology. Among five dimensions in the scale they used, the knowledge of technology was found to have the least mean score. Also, the present study indicated a single response related to the use of SI prefixes 
for calculating the electrical energy consumed. This finding shows similarity with what was obtained from the study by Lay, Khoo, Treagust and Chandrasegaran (2013). The researchers found that only $13 \%$ of secondary school students could determine the correct unit for measuring the amount of electrical energy.

The application of the Sudoku puzzles to biology teaching students resulted in the achievement of the majority of the participants (90\%) for completing the puzzles. Considering the fact that the study group takes introductory science courses related to biology and chemistry, it is thought that the success obtained from $90 \%$ of the participants might confirm the applicability of the puzzles. Also, the responses of the participants in relation to the difficulty of the puzzles correlate with the time they devoted to completing each puzzle. Participants generally found Sudoku 2 more difficult and they spent more time (30 minutes) to complete it when compared to the findings related to the Sudoku 1 (23 minutes). The reason for determining Sudoku 2 as a more difficult puzzle might be due to the fact that it involved a Greek letter, $\mu$, as a symbol, whereas Sudoku 1 only consisted of Latin letters as symbols. The participants' difficulty with Sudoku 2 which involved a Greek letter as a symbol is similar to the finding obtained from Brophy and Hahn's (2014) study. Those researchers determined that the students gave more correct responses to the number-based Sudoku puzzle, which was followed by Latin letters, symbols and Greek letter-based Sudoku puzzles.

When the participants' experiences in relation to Sudoku puzzles are evaluated, it is seen that positive results are obtained from all of them in terms of both cognitive and affective aspects. Considering the cognitive influences, the Sudoku puzzles were found to make the participants mentally active and use their visual intelligence. Those outcomes are expected to support student achievement as found in the previous literature (Coskun et al., 2012; Yazicioglu \& Cavus-Gungoren, 2012). Moreover, providing students with instruments to enhance their learning and overcome memorisation is in line with the studies of Karamustafaoglu et al. (2018) and Ogunleye (2009). In terms of affective aspects, the participants expressed their pleasure for attending the Sudoku activity. This finding is expected to provide motivation for the participants towards learning as highlighted earlier (Bulus Kirikkaya, Iseri \& Vurkaya, 2010; Yazicioglu \& Cavus-Gungoren, 2012) for solving numerical problems and interpreting various quantities encountered in the science courses. On the other hand, experiencing difficulty at the beginning of the activity was also among the participants' responses by adding that they were not familiar with such type of activities. Hence, it is thought that the activity also supplied the acquaintance of those students with the Sudoku puzzles.

\section{Conclusion}

To conclude, the Sudoku puzzles developed in the present study are expected to contribute to undergraduate students' science education in the form of a mental game. The puzzles can be utilised in terms of both introductory physics and chemistry courses. The present study reports their application in the context of a chemistry laboratory course. The findings imply the applicability and benefits of the Sudoku puzzles on the participants.

\section{Recommendations}

In this study, the Sudoku puzzles were applied as a case study with a limited number of students. It is suggested to make to make applications on larger samples which might be conducted on online platforms in the future. In addition, the Sudoku puzzles suggested in this article might be utilised for the students in different grade levels and with different educational needs after conducting pilot studies. First, the Sudoku puzzles might be used for the education of gifted learners at high school level. Also, the Sudoku puzzles might be generated in the tactile form for the individuals with visual impairment taking introductory science courses.

Finally, the suggested puzzles might be designed to make use of the numbers, symbols and letters at the same time. Thus, it might be possible for students to improve their ability to make transitions 
between the numerical world and symbolic world continuously with the addition of extra challenges to the puzzles.

\section{References}

Abdukadyrov, A. (2018). Progress of the SI and CGS systems: Conversion of the MKSA units to the MKS and CGS units. American Journal of Electromagnetics and Applications, 6(1), 24-27. Doi: 10.11648/j.ajea.20180601.14

Bagno, E., Berger, H., \& Eylon, B.-S. (2008). Meeting the challenge of students' understanding of formulae in high-school physics: a learning tool. Physics Education, 43(1), 75-82. Retrieved from https://iopscience.iop.org/article/10.1088/0031-9120/43/01/008/pdf

Bittar, T. J., Lobato, L. L., Brum, R. P., Peres, D. A., Cintra, A. R., \& Longo, E. (2009). Development of two educational web games: Chemical Sudoku and nanotechnology puzzle. Proceedings of $11^{\text {th }}$ International Conference on Advanced Materials. Rio de Janerio, Brasil. Retrieved from https://www.sbpmat.org.br//icam2009dir/submission/palestrante/arquivos/PAA11.pdf

Brophy, C., \& Hahn, L. (2014). Engaging students in a large lecture: an experiment using Sudoku puzzles. Journal of Statistics Education, 22(1), 1-20. https://doi.org/10.1080/10691898.2014.11889690.

Bulus Kirikkaya, E., Iseri, S., \& Vurkaya, G. (2010). A board game about space and solar system for primary school. TOJET: The Turkish Online Journal of Educational Technology, 9(2), 1-13. Retrieved from http://www.tojet.net/articles/v9i2/921.pdf

Buyukozturk, S., Kilic Cakmak, E., Akgun, O. E., Karadeniz, S., \& Demirel, F. (2010). Bilimsel araştırma yöntemleri [Scientific research methods]. Ankara: PegemA.

Christensson, P. (2013, February 26). Gigabyte Definition. Retrieved from https://techterms.com

Chytry, V. (2014). Sudoku 2014 game solution based on graph theory and suitable for school-mathematics. In 0. Sedivy, V. Svecova, D. Vallo, \& K. Vidermanova (Eds.), Proceedings of ACTA MATHEM ATICA 17 (pp. 5560). Nitra, Slovakia. Retrieved from http://www.nmk.fpv.ukf.sk/2014/proceedings/6_chytry_fulltext.pdf

Coramik, M., \& Ozdemir, E. (2020). Öğretmen adaylarının temel birimler ve önekler ile ilgili bilgi düzeylerinin belirlenmesi [Determination of pre-service teachers' knowledge level of "SI" base units and prefixes]. Cumhuriyet International Journal of Education, 9(3), 729-754. http://dx.doi.org/10.30703/cije.642120

Coskun, H., Akarsu, B., \& Kariper, i. A. (2012). Bilim öyküleri içeren eğitsel oyunların fen ve teknoloji dersindeki öğrencilerin akademik başarılarına etkisi [The effects of educational games based on science stories on students' academic achievements in science and technology classroom]. Ahi Evran Üniversitesi Kırşehir Eğitim Fakültesi Dergisi (KEFAD) [Ahi Evran University Kırşehir Education Faculty Journal], 13(1), 93-109. Retrieved from http://kefad.ahievran.edu.tr/InstitutionArchiveFiles/f44778c7-ad4a-e711-80ef00224d68272d/d1a3a581-af4a-e711-80ef-00224d68272d/Cilt13Sayi1/JKEF_13_1_2012_93_109.pdf

Crute, T. D., \& Myers, S. A. (2007). Sudoku puzzles as chemistry learning tools. Journal of Chemical Education, 84(4), 612-613. https://doi.org/10.1021/ed084p612

de Freitas, S. (2018). Are games effective learning tools? A review of educational games. Educational Technology \& Society, 21(2), 74-84. Retrieved from https://www.jstor.org/stable/pdf/26388380.pdf?refreqid=excelsior\%3A479ec345f5966bd048e266e867 a1596f

Delgado, C. (2013). Cross-cultural study of understanding of scale and measurement: Does the everyday use of us customary units disadvantage us students?. International Journal of Science Education, 35(8), 12771298. https://doi.org/10.1080/09500693.2013.779761.

Ebbing, D. D., \& Gammon, S. D. (2002). General chemistry (7 $7^{\text {th }}$ Ed.). Boston: Houghton Mifflin Company. 
Urek, H. (2020). Sudoku puzzles for practicing SI prefixes: A case study with Turkish undergraduates. Cypriot Journal of Educational Science, 15(5), 1065-1077. https://doi.org/10.18844/cjes.v15i5.5152

Ernstberger, K. W., \& Venkataramanan, M. A. (2018). Announcing the engagement of Sudoku: an in-class genetic algorithm game. Decision Sciences Journal of Innovative Education, 16(3), 185-196. Retrieved from https://onlinelibrary.wiley.com/doi/epdf/10.1111/dsji.12160

Evans, R., Lindner, B., \& Shi, Y. (2011). Generating Sudoku puzzles and its applications in teaching mathematics. International Journal of Mathematical Education in Science and Technology, 42(5), 697-704. https://doi.org/10.1080/0020739X.2011.562316.

Furio, C., Azcona, R., \& Guisasola, J. (2002). The learning and teaching of the concepts amount of substance and mole: A review of the literature. Chemistry Education: Research and Practice in Europe, 3(3), 277-292. Retrieved from https://pubs.rsc.org/en/content/articlepdf/2002/rp/b2rp90023h

Guven, Y., Gultekin, C., \& Dedeoglu, A. B. (2020). Comparison of Sudoku solving skills of preschool children enrolled in the Montessori approach and the national education programs. Journal of Education and Training Studies, 8(3), 32-47. https://doi.org/10.11114/jets.v8i3.4620

Incantalupo, L., Treagust, D. F., \& Koul, R. (2014). Measuring student attitude and knowledge in technology-rich biology classrooms. Journal of Science Education and Technology, 23, 98-107. Doi: 10.1007/s10956-0139453-9.

Jolliff, T. (2007). Chemistry for the gifted and talented. London: Royal Society of Chemistry.

Karamustafaoglu, O., Pazar, S. B., \& Karamustafaoglu, S. (2018). Eğitsel oyunlarla dolaşım sistemi konusunun öğretimi: Kan yolu oyunu örneği [Teaching of the circulatory system with educational games: blood road play]. Journal of Education in Eskisehir Osmangazi University Turkic World Apply and Research Center, 3(2), 1-18. Retrieved from https://dergipark.org.tr/tr/download/article-file/571359

Lay, Y.-F., Khoo, C.-H., Treagust, D. F., \& Chandrasegaran, A. L. (2013). Assessing secondary school students' understanding of the relevance of energy in their daily lives. International Journal of Environmental \& Science Education, 8(1), 199-215. Retrieved from https://files.eric.ed.gov/fulltext/EJ1008601.pdf

Lee, N. Y. L., Goodwin, G. P., \& Johnson-Laird, P. N. (2008). The psychological puzzle of Sudoku. Thinking \& Reasoning, 14(4), 342-364. Doi: 10.1080/13546780802236308.

Ogunleye, A. O. (2009). Teachers' and students' perceptions of students' problem-solving difficulties in physics: implications for remediation. Journal of College Teaching \& Learning, 6(7), 85-90. Retrieved from https://core.ac.uk/download/pdf/268110475.pdf

Oguzhan Dincer, E., \& Osmanoglu, A. (2018). Dealing with metric unit conversion: An examination of prospective science teachers' knowledge of and difficulties with conversion. Science Education International, 29(3), 174-182. Retrieved from http://www.icaseonline.net/journal/index.php/sei/article/view/59

Perez, A. L., \& Lamoureux, G. (2007). Sudoku puzzles for first-year organic chemistry students. Journal of Chemical Education, 84(4), 614. https://doi.org/10.1021/ed084p614

Petrucci, R. H., Herring, F. G., Madura, J. D., \& Bisonnette, C. (2012). Genel kimya ilkeler ve modern uygulamalar cilt 1 (General chemistry, principles and modern applications volume 1) (Trans. Ed.: T. Uyar, S. Aksoy \& R. Inam). Ankara: Palme Yayıncilık.

Rukavina, S., Zuvic-Butorac, M., Ledic, J., Milotic, B., \& Jurdana-Sepic, R. (2012). Developing positive attitude towards science and mathematics through motivational classroom experiences. Science Education International, 23(1), 6-19. Retrieved from https://files.eric.ed.gov/fulltext/EJ975543.pdf

Serway, R. A., \& Beichner, R. J. (2002). Fen ve mühendislik için fizik 1 (Physics 1 for scientists and engineers) (Trans. Ed. K. Colakoglu). Ankara: Palme Yayıncilık.

Snyder, B. A. (2010). Using sudoku to introduce proof techniques. PRIMUS, 20(5), 383-391. https://doi.org/10.1080/10511970802326145. 
Stanford, A. L., \& Tanner, J. M. (2014). Physics for students of science and engineering. Orlando, Florida: Academic Press, Inc.

Steele, A., \& Wood, B. (2020, September). The impact of the new SI in the measurement sector. IEEE Instrumentation \& Measurement Magazine, 3-9.

Tan Sisman, G., \& Aksu, M. (2016). A study on sixth grade students' misconceptions and errors in spatial measurement: length, area, and volume. International Journal of Science and Mathematics Education, 14, 1293-1319. Doi: 10.1007/s10763-015-9642-5

Tech Terms. (2012, October 13). What units of measurement are used for data storage?. Retrieved 2020, May 20, from https://techterms.com

Tengah, K. A. (2011). Using simplified Sudoku to promote and improve pattern discovery skills among school children. Journal of Mathematics Education at Teachers College, 2(1), 53-62. https://doi.org/10.7916/jmetc.v2i1.710

Thompson, A., \& Tyler, B. N. (2008). Guide for the use of the international system of units (SI). National Institute of Standards and Technology Gaithersburg, MD 20899. Retrieved from https://physics.nist.gov/cuu/pdf/sp811.pdf

Urek, H., \& Dolu, G. (2018). Gaz yasalarıyla ilgili geleneksel ve bağlam temelli problemlerin çözülebilme durumuna yönelik bir araştırma [A study about the case of solution of the traditional and context based gas law problems]. Mersin University Journal of the Faculty of Education, 14(1), 19-34. https://doi.org/10.17860/mersinefd.290270

Welsh, M. J. (2007). Chemistry of art and color Sudoku puzzles. Journal of Chemical Education, 84(4), 610-611. https://doi.org/10.1021/ed084p610

Wu, Y., Zhou, Y., Agaian, S., \& Noonan, J. P. (2016).2D Sudoku associated bijections for image scrambling. Information Sciences, 327, 91-109. http://dx.doi.org/10.1016/j.ins.2015.08.013

Yazicioglu, S., \& Cavus-Gungoren, S. (2019). Oyun temelli etkinliklerin ortaokul öğrencilerinin fen öğrenmesine olan etkisini başarı, motivasyon, tutum ve cinsiyet değişkenlerine göre incelenmesi [Investigate the effect of game-based activities on middle school students' science learning according to achievement, motivation, attitude and gender variables]. Necatibey Faculty of Education Electronic Journal of Science and Mathematics Education, 13(1), 389-413. https://doi.org/10.17522/balikesirnef.584673

Yildirim, A., \& Simsek, H. (2008). Sosyal bilimlerde nitel araştırma yöntemleri (Qualitative research methods in social sciences). Ankara: Seçkin Yayıncılık. 